\title{
In response to "Obstructive sleep apnea syndrome should always be screened in patients complaining of nocturia". World J Urol. 2018
}

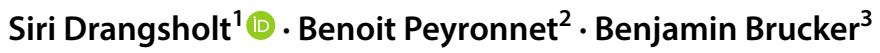

Received: 2 January 2019 / Accepted: 3 January 2019 / Published online: 17 January 2019

๑) Springer-Verlag GmbH Germany, part of Springer Nature 2019

Dr. Misrai et al. draws attention to obstructive sleep apnea syndrome (OSAS) as an under-recognized entity that can lead to nocturia. They correctly state that if OSAS is present, the initial management would usually not be a pharmacological treatment. Although we did not use a validated screening tool such as the Berlin Questionnaire, taking a sleep history is standard for our nocturia evaluation. In our retrospective cohort of 403 diverse patients, we found that a history of sleep disorder was associated with higher baseline nocturia events. The retrospective nature and method of identifying patients may inherently lead to a lower rate of OSAS, as patients who were felt to have had another underlying medical condition (i.e., OSAS) may have left the visit with a diagnosis code of something other than nocturia. While it is possible that some in our cohort had undiagnosed sleep apnea, only $8.4 \%$ of our population was obese and most patients were female (59\%). Male gender and obesity are consistently recognized risk factors $[1,2]$, only $8.4 \%$ of our population was obese and most patients in our cohort were female (59\%). When studying nocturia, we should realize that practice patterns (such as an emphasis on primary care screening or access to specialist care) may influence the patients who are included in a single-center study.
Interestingly, if we consider the large multicenter studies of the newly formulated desmopressin in patients with nocturia, subjects were excluded if they had the diagnosis of OSAS, but routine screening for OSAS with a validated questionnaire was not included in the methods they present. In spite of this, patients had an improvement in their symptoms and quality-of-life measures [3].

\section{References}

1. Peppard PE, Young T, Palta M et al (2000) Longitudinal study of moderate weight change and sleep-disordered breathing. JAMA 284:3015-3021

2. Young T, Palta M, Dempsey J et al (1993) The occurrence of sleep-disordered breathing among middle-aged adults. N Engl J Med 328:1230-1235

3. Kaminetsky J, Fein S, Dmochowski R, MacDiarmid S et al (2018) Efficacy and safety of SER120 nasal spray in patients with nocturia: pooled analysis of 2 randomized, double-blind, placebo controlled, phase 3 trials. J Urol 3:604-611
Siri Drangsholt

Siri.Drangsholt@nyumc.org

1 Department of Urology, New York University School of Medicine, 222 E 41s St, 11th Floor, New York, NY 10017, USA

2 Department of Urology, University of Rennes, Rennes, France

3 Division of Female Pelvic Medicine and Reconstructive Surgery, New York University Langone Medical Center, New York, NY, USA 